\title{
Higher Physical Activity of School Personnel Is Related to More Positive Attitudes towards Children's Physical Activity at School
}

\author{
Getter Marie Lemberg ${ }^{1, *}$, Merike Kull ${ }^{1}$, Katrin Mägi ${ }^{1}$, Henri Tilga ${ }^{1}\left(\mathbb{O}\right.$, Kerli Mooses $^{2}$ and Evelin Mäestu ${ }^{1} \mathbb{C}$ \\ 1 Institute of Sport Sciences and Physiotherapy, Faculty of Medicine, University of Tartu, 51008 Tartu, Estonia; \\ merike.kull@ut.ee (M.K.); katrin.magi@ut.ee (K.M.); henri.tilga@ut.ee (H.T.); evelin.maestu@ut.ee (E.M.) \\ 2 Institute of Computer Science, Faculty of Science and Technology, University of Tartu, 51009 Tartu, Estonia; \\ kerli.mooses@ut.ee \\ * Correspondence: getter.marie.lemberg@ut.ee
}

\section{check for} updates

Citation: Lemberg, G.M.; Kull, M.; Mägi, K.; Tilga, H.; Mooses, K.; Mäestu, E. Higher Physical Activity of School Personnel Is Related to More Positive Attitudes towards Children's Physical Activity at School. Sustainability 2021, 13, 10909. https:/ / doi.org/10.3390/su131910909

Academic Editors:

Pedro Valdivia-Moral and Jose Luis Ubago

Received: 18 August 2021

Accepted: 27 September 2021

Published: 30 September 2021

Publisher's Note: MDPI stays neutral with regard to jurisdictional claims in published maps and institutional affiliations.

Copyright: (c) 2021 by the authors. Licensee MDPI, Basel, Switzerland. This article is an open access article distributed under the terms and conditions of the Creative Commons Attribution (CC BY) license (https:// creativecommons.org/licenses/by/ $4.0 /)$.

\begin{abstract}
School personnel can struggle with meeting the daily physical activity recommendation; however, they are role models for students, and their attitudes towards physical activity can impact students' physical activity habits. The aim was to assess school personnel's physical activity and their attitudes regarding the importance of physical activity among students. The physical activity levels of 1030 school employees in Estonia were assessed using an accelerometer. Participants also responded to a questionnaire about physical activity habits, overall health, and attitudes about the importance of physical activity among students. About $92.6 \%$ of the participants met the World Health Organisation's weekly physical activity recommendation. However, 69.1\% of the accelerometer wearing time was spent being sedentary. Only $5.8 \%$ of the wearing time was spent in moderate to vigorous physical activity. More active school personnel believed their lead affects students' attitudes towards physical activity $(\mathrm{r}=0.072-0.156, p<0.05)$ and being active at recess facilitates a peaceful learning environment in the classroom $(r=0.064-0.072, p<0.05)$. Whereas more sedentary school personnel did not encourage students to be active at recess $(r=-0.073$, $p<0.05)$. More active school personnel had more positive attitudes towards physical activity, which demonstrates the importance of focusing on encouraging physical activity among school personnel as they can affect the behaviour of students.
\end{abstract}

Keywords: physical activity; teachers; school personnel; accelerometers; attitude

\section{Introduction}

Even though physical activity (PA) has been found to have many health benefits, according to the World Health Organisation (WHO), globally, 1 in 4 adults do not meet the recommended levels of PA [1]. Regular participation in moderate-intensity PA can improve overall health [2] and mental health [3] and reduce the risk of chronic diseases [2]. The WHO recommends that adults engage in at least 150-300 min of moderate-intensity PA, or at least 75-150 min of vigorous-intensity PA, or an equivalent combination of moderateand vigorous-intensity activity throughout the week, for substantial health benefits [4]. A systematic review by Prince and colleagues [5] found that working adults spent about $60 \%$ of their working and waking time engaged in sedentary behaviour and only about $4 \%$ of the day included moderate to vigorous PA (MVPA).

School personnel spend most of their day in the school environment and can struggle with meeting the recommended PA levels due to the nature of their occupation. Studies conducted in different regions of the world have implicated that occupational factors can affect the health status of teachers [6-10] and office workers [5]. Teachers and those with mostly desk-based occupations (e.g., administration, office staff) in schools most commonly self-report disorders of the musculoskeletal system [11,12]. Causes of the musculoskeletal problems among school personnel can be attributed to sedentary behaviour. 
Teachers oftentimes work extra hours to prepare for the next day, which might make it difficult for them to find time to engage in PA [13]. Studies about teachers' PA levels are scarce, but some have been conducted among public school teachers around the world [8,14-20]. Studies in Brazil found the prevalence of 46-55\% of low activity and sedentary behaviour among public school teachers $[8,14,16]$, the prevalence was even higher among male teachers, reaching 69.5\% [8]. Among university staff in the United Kingdom, 42\% reported activity levels below the recommended guidelines [21].

The aforementioned studies have demonstrated the need for teachers and school personnel to have more opportunities to be active throughout their day. Many PA interventions and programmes in schools focus solely on students but should be more comprehensive and include the PA needs of school personnel. An example of a more comprehensive school-based PA intervention programme is the Schools in Motion programme in Estonia, which "supports the participating schools in redefining and designing the schools' practices and conditions in a PA-supportive way and in offering more PA opportunities for students and personnel through a systematic approach" [22]. The programme provides seminars and workshops for school personnel, in order to decrease sedentary time during academic lessons and recess and to support changes in the indoor and outdoor environment to provide more opportunities for PA throughout the school day [22].

Similarly to school personnel, children also spend most of their day in schools, where teachers play a key role in their development and can affect students' behaviour [22-24]. The idea that a teachers' behaviour can influence the way in which students behave is supported by social cognitive theory [25], which suggests that the social environment plays a role in shaping students' behaviour. Therefore, as children spend a lot of time in the school environment and interact a lot with teachers, teachers can be considered positive role models for students when it comes to PA behaviour [24]. A positive example of teachers' and administrators' PA behaviour can be a helping factor to make children's schooldays more active and encourage students to engage more in PA throughout their day. Administrators might not engage as much with students as teachers do, but their positive beliefs about PA can change the structure of the school day to one that is more physically active [22].

Schools in Estonia are traditional, with most of the learning done within the classrooms. Outdoor learning and active teaching methods are not commonly used, but the education system is actively moving towards providing more of these teaching methods within schools [22]. However, as active learning is not so common yet, engaging in PA during the school day can be difficult for the school personnel. Full-time teachers in Estonia work $35 \mathrm{~h}$ within a 7-day time period, and their workhours include teaching, preparing for lessons, and grading students' work [26]. The majority of teachers in Estonia are female, making up about $87.1 \%$ of all teachers in Estonia [27].

To our best knowledge, the current study is one of the few in the world and the first study in Estonia that has looked closely at the PA levels of teachers and other school personnel and their attitudes about the importance of PA among students. The aim of the study was (1) to describe the PA levels of school personnel and compare these levels between subgroups, (2) to explore the attitudes of school personnel subgroups about providing PA opportunities for students throughout the school day, and (3) to explore the relationship between the PA levels of school personnel and their attitudes towards providing PA opportunities to students within the school. The results of the study are important for understanding the PA habits of the school personnel and their perceptions of the importance of PA among students and to gain more insight for planning and creating new comprehensive school-based PA intervention programmes.

\section{Methods}

\subsection{Participants}

Data collection for this cross-sectional study was performed between September 2019 and March 2020. In total, 78 Estonian schools all around the country from the Schools in 
Motion network [22] were asked to participate in this study. The design and the aim of the Schools in Motion programme has been explained in an article describing the design of the programme in detail [22]. More than half, i.e., 44 schools out of 78, agreed to participate. All members of the school personnel had the opportunity to participate in the study and received written information about the study. Of these 44 schools, in total, 1190 school employees agreed to participate in the study. All participants were asked to wear the accelerometer and fill out the questionnaire. In total, valid accelerometer data and/or questionnaire responses were obtained from 1030 participants (118 men and 912 women). Participants whose data was not included in the analysis did not wear the accelerometer or did not have enough accelerometer data (at least four days including three workdays and one weekend day of at least ten hours of wear time per day) or had not filled out the questionnaire or missed replying to multiple questions. Participants of the study were grouped into four groups based on their occupation in school: (1) administration ( $N=103$; includes, e.g., the head of school, deputy head, head of development, and human resources); (2) office staff ( $\mathrm{N}=36$; secretaries, assistants, other office workers); (3) teachers ( $\mathrm{N}=782$; subject teachers and homeroom teachers); and (4) support staff $(\mathrm{N}=109$; e.g., social worker, speech therapist, psychologist).

Written informed consent was obtained from all participants. The study was performed in accordance with the Declaration of Helsinki [28] and was approved by the Medical Ethics Committee of the University of Tartu, Tartu, Estonia, approval no. 295/T-4.

\subsection{Procedures}

A quantitative approach was used in this study to get data about teachers' PA habits. Daily PA was measured with a GT3X accelerometer, which school personnel wore for seven consecutive days during the time they were awake. During the accelerometer wearing period, participants kept a paper diary to describe their daily routines of sleep, working hours, leisure time sports activities, and non-wear time of the devices. In addition, a questionnaire was used to learn more about school personnel's perceptions about PA.

\subsection{Physical Activity Measurements}

The accelerometer is one of the most commonly used and easily accessible methods to objectively measure PA [29-31]; therefore, the ActiGraph GT3X accelerometer (ActiGraph LLC, Pensacola, FL, USA) [30] was used to monitor PA and sedentary time during waking hours. In addition to PA and sedentary time, steps per day were also measured. For the accuracy of the methodology, only one type of accelerometer was used. After the 7-day wearing period in school, the accelerometers were collected and data were downloaded, then they were initialised again and delivered to the next subjects. A total of 192 accelerometers were in use. Participants were instructed that they do not have to wear the device during the night, and they wore the device on a belt around the waist for seven consecutive days. Since the used device is not waterproof, participants were asked to remove the device for water-based activities. A valid recording for PA and sedentary time required at least four days (including three workdays and one weekend day) of at least ten hours of wear time per day [32,33]. The accelerometer data were analysed using activity counts of 15 s epochs. All sequences of 20 min or more of consecutive zero counts were excluded from each individual's recording [32]. Time spent at different PA intensities per day was calculated using Freedson's cut points [34]. Total daily physical activity (Total PA) was calculated as the total number of counts divided by the registered time (counts/min). Sedentary time, light PA, moderate PA, and vigorous PA were considered when counts per minute (cpm) accumulation was $<100$ cpm, 100-1951 cpm, 1952-5724 cpm, and >5724 cpm, respectively [34]. Each individual's accumulated PA was categorised into different intensities, and average minutes per day (min/day) of sedentary time, moderate PA, and vigorous PA over valid days were calculated subsequently. Time spent in MVPA was calculated as the sum of moderate PA and vigorous PA. The daily percentage of all PA intensity levels was calculated after summarising the time spent at every intensity level including 
sedentary time [35]. To meet the current PA guidelines, at least 150 min of moderate PA or at least $75 \mathrm{~min}$ of vigorous PA for a week was required [4].

\subsection{Questionnaire}

Participants completed the questionnaire including questions about demographics, leisure time PA, active transportation, satisfaction with health, and perceptions of PA among students. The questionnaire was developed and validated by the Schools in Motion programme and has been previously used in other studies conducted by them [22]. Questions about demographics included the age and gender of the participant and their occupation in the school.

The next section in the questionnaire included information about school personnel's leisure time. School personnel were asked "How often do you participate in physical activity for at least $30 \mathrm{~min}$, in a way that you start breathing a little harder and start sweating?" Participants had to pick between the answers such as (1) every day, (2) 4-6 times a week, (3) 2-3 times a week, (4) once a week, (5) 2-3 times a month, (6) few times a year or not at all, and (7) cannot engage in physical activity due to an illness or an injury.

The section about active transportation included three questions. Participants were asked "If you think about last month, how did you usually go to work and get home from work, and how long did it take?" Responses included options such as (1) by car, (2) by public transportation, (3) by bicycle, scooter, skateboard, and (4) by walking. Participants had to report their one main choice of transportation for both going to work and going back home after work and report the time spent on it. The next question asked the participants "How many minutes a day do you usually spend on active transportation?" Participants had to report the hours and minutes on average spent on active transportation. The last question of this section was "What mode of active transportation do you usually use?" and the responses included (1) walking, (2) riding a bicycle, (3) riding a scooter, and 4) riding an electric vehicle (electric bicycle, hoverboard, or other).

The section about satisfaction with health included a question "In general, how satisfied are you with your health?" Responses included options such as (1) very satisfied, (2) satisfied, (3) unsatisfied, (4) very unsatisfied, and (5) do not know. Participants were also asked to report their height and weight.

In the last section of the questionnaire, participants were asked to rate statements about PA among students on a five-point Likert scale. The statements used were the following: (1) every employee in our school is responsible for supporting opportunities for students to be active, (2) my example/lead affects students' attitudes towards physical activity, (3) if students cannot move during class, their ability to focus decreases, (4) using methods that allow being active in classroom is wasting time that is needed for learning, (5) it is beneficial for students to go outside during recess, (6) opportunities for being active at recess facilitate better relationships among students, (7) being active at recess facilitates a peaceful learning environment in the classroom, (8) allowing students to be active at recess means extra work for teachers, and (9) I encourage students to be active at recess.

\subsection{Statistical Analysis}

Statistical analysis was performed using IBM SPSS Statistics software, version 26 (Armonk, NY, USA: IBM Corp). Homogeneity of variance was tested using Levene's test. Normality was tested using the Shapiro-Wilk test. Descriptive statistics of the participants are presented as mean and standard deviation (SD). Analysis of covariance (ANCOVA) was used to examine possible differences in the physical activity parameters in the subgroups after adjustment for accelerometer wear time. To determine the statistical difference between subgroups in categorical data, the chi-square statistic was used. Bivariate correlations were computed between sedentary behaviour and physical activity parameters and the questions about the administration's, teachers', and support staff's promotion and encouragement of children's physical activity in the school environment. Significance was set as $p<0.05$. 


\section{Results}

The total number of participants in the study was 1030 , and $87.1 \%$ of the participants were female (Table 1). Participants were grouped based on their occupation in school with the biggest group being teachers, $75.9 \%$ of all the participants. Out of all the teachers, 116 $(14.8 \%)$ taught physical education. The age of the participants ranged from 19 to 81 years, with an average age of 45.2 (12.7) years.

Table 1. Descriptive statistics of studied school personnel. Values are presented as mean and standard deviation (SD).

\begin{tabular}{cccc}
\hline & Female $(\boldsymbol{n}=\mathbf{9 1 2})$ & Male $(\boldsymbol{n}=\mathbf{1 1 8})$ & Total $(\boldsymbol{n}=\mathbf{1 0 3 0})$ \\
\hline Age $($ years $)$ & $45.6(12.6)$ & $41.9(12.6) *$ & $45.2(12.7)$ \\
Height $(\mathrm{cm})$ & $167.2(6.0)$ & $181.0(6.7) *$ & $168.8(7.5)$ \\
Weight $(\mathrm{kg})$ & $71.1(14.0)$ & $86.7(14.3) *$ & $72.9(14.9)$ \\
BMI $\left(\mathrm{kg} / \mathrm{m}^{2}\right)$ & $25.4(4.8)$ & $26.5(4.0) *$ & $25.5(4.7)$ \\
\hline
\end{tabular}

Notes: BMI—body mass index. * Significantly different from females; $p<0.05$.

The average daily amount of time all groups spent in different PA intensities is demonstrated in Table 2. The average wearing time of the accelerometer was 855.3 (80.2) min/day. Most of the accelerometer wearing time was spent being sedentary (69.1\%), with the most sedentary group being the administration, spending daily on average $70.1 \%$ of wearing time sedentary. Only $5.8 \%$ of the total wearing time accounted for MVPA in which more time was spent in moderate PA (5.5\%) than in vigorous PA $(0.3 \%)$. Out of all the groups, the administration spent the most time in MVPA (6.1\%) of total wearing time. About $92.6 \%$ of the school staff met the current weekly recommendation of at least $150 \mathrm{~min}$ of moderate PA a week. The only significant difference $(p<0.05)$ in PA intensity was for light intensity for teachers and support staff compared to that for the administration (Table 2).

Table 2. Descriptive statistics of school personnel's objectively measured physical activity parameters. Descriptive values are presented as mean and standard error (SE) and mean and standard deviation (SD) for wear time.

\begin{tabular}{ccccc}
\hline Variables & Teachers & Administration & Support Staff & Office Staff \\
\hline Sedentary behaviour (min/day) & $591.8(2.0)$ & $602.8(5.6)$ & $582.9(5.5) *$ & $589.6(9.6)$ \\
Light PA (min/day) & $215.0(1.7) *$ & $202.4(4.6)$ & $223.8(4.6)^{*}$ & $217.7(7.9)$ \\
Moderate PA (min/day) & $46.6(0.8)$ & $48.7(2.2)$ & $47.0(2.2)$ & $46.8(3.7)$ \\
Vigorous PA (min/day) & $3.1(0.2)$ & $2.5(0.6)$ & $2.9(0.6)$ & $2.3(1.0)$ \\
MVPA (min/day) & $49.7(0.8)$ & $52.3(2.4)$ & $49.8(2.3)$ & $49.2(4.1)$ \\
Total PA (counts/min) & $361.9(4.9)$ & $358.8(13.6)$ & $369.4(13.3)$ & $357.8(23.2)$ \\
Steps (day) & $8342(99)$ & $8355(274)$ & $8406(273)$ & $8358(472)$ \\
Accelerometer wear time (min/day) & $857.7(81.1)$ & $856.2(71.6)$ & $845.4(83.7)$ & $828.4(69.2){ }^{\dagger}$
\end{tabular}

Notes: Physical activity and steps values are adjusted for accelerometer wear time, gender, age, and BMI * Significantly different from administration. ${ }^{+}$Significantly different from teachers. $p<0.05$.

According to the answers to the questionnaire, at least half of the participants in all groups reported participating in at least moderate-intensity PA for at least $30 \mathrm{~min}$ in leisure time at least twice a week, i.e., 55.1\% of teachers and administration, 51.8\% of support staff, and 50\% of office staff, respectively (Table 3). More than half of the school personnel choose a car as the main transportation to go to work and go back home. Support staff and office staff were the most likely to go to work on foot. The support staff were most satisfied with their health, as more than $80 \%$ reported having good or rather good health (Table 3$)$. There was a significant difference $(p<0.05)$ in self-evaluated good or rather good health for teachers compared to the administration and for office staff compared to support staff and teachers. There was no significant difference in all other self-evaluated parameters between groups $(p \geq 0.05)$. In all groups, more PA (more total PA, moderate PA, vigorous PA, and MVPA) was positively related to better self-assessed health $(r=0.133-0.242, p \leq 0.041)$, and more sedentary time was associated with worse self-assessed general health $(r=0.081-0.146, p \leq 0.013)$. 
Table 3. Descriptive statistics of school personnel's leisure time PA, active transportation, and self-assessed health.

\begin{tabular}{|c|c|c|c|c|}
\hline Variables & Teachers & Administration & Support Staff & Office Staff \\
\hline \multicolumn{5}{|c|}{ Doing at least moderate intensity physical exercises for at least $30 \mathrm{~min}$ in leisure time } \\
\hline At least 4 times a week (\%) & 18.7 & 17.3 & 16.0 & 14.7 \\
\hline $2-3$ times a week $(\%)$ & 36.4 & 37.8 & 35.8 & 35.3 \\
\hline Once a week (\%) & 18.8 & 18.4 & 20.8 & 29.4 \\
\hline A few times a month or less $(\%)$ & 22.6 & 24.5 & 24.5 & 17.6 \\
\hline Cannot exercise due to injury or illness (\%) & 3.5 & 2.0 & 2.8 & 2.9 \\
\hline \multicolumn{5}{|c|}{ How do you usually go to work? } \\
\hline Car $(\%)$ & 62.5 & 64.6 & 58.1 & 51.4 \\
\hline Public transport (\%) & 11.7 & 6.3 & 12.4 & 14.3 \\
\hline Bicycle, scooter, skateboard (\%) & 3.7 & 6.3 & 2.9 & 2.9 \\
\hline On foot $(\%)$ & 22.1 & 22.9 & 26.7 & 31.4 \\
\hline \multicolumn{5}{|c|}{ How do you usually go back home? } \\
\hline Car $(\%)$ & 59.6 & 61.1 & 54.0 & 54.3 \\
\hline Public transport (\%) & 11.7 & 7.4 & 13.0 & 17.1 \\
\hline Bicycle, scooter, skateboard (\%) & 4.1 & 5.3 & 3.0 & 2.9 \\
\hline On foot $(\%)$ & 24.6 & 26.3 & 30.0 & 25.7 \\
\hline \multicolumn{5}{|c|}{ Self-assessment of general health } \\
\hline Good/rather good (\%) & 82.7 & $78.4^{*}$ & 86.7 & $61.8^{*,+}$ \\
\hline Cannot evaluate (\%) & 0.7 & $4.1 *$ & 1.0 & 2.9 \\
\hline $\mathrm{Bad} / \mathrm{rather}$ bad (\%) & 16.6 & 17.5 & 12.4 & $35.3 *+$ \\
\hline
\end{tabular}

Notes: * Significantly different from teachers. ${ }^{+}$Significantly different from support staff; $p<0.05$.

School personnel's perceptions about promoting and encouraging PA among students in schools are presented in Figure 1. Responses from the office staff were excluded from results in this section as they are not in contact with students as much as the other groups. Most of the participants in the administration, teachers, and support staff groups believed that every employee in their school was responsible for supporting opportunities for students to be active, whereas the administration agreed with this statement significantly more $(p<0.05)$ than teachers' and support staff. More than two-thirds of participants in all three groups agreed that students' ability to focus decreases if they cannot move during class; however, teachers agreed with it significantly less $(p<0.05)$ than the administration. All groups agreed that opportunities for being active at recess facilitate better relationships among students, but the teachers' and support staff's response was significantly lower $(p<0.05)$ compared to that of the administration. Over $90 \%$ of the administration believed that being active at recess facilitates a peaceful learning environment in the classroom. Teachers and support staff also highly agreed with this statement; however, their response was significantly lower $(p<0.05)$ compared to that of the administration.

Results of bivariate correlations of school personnel's PA parameters and sedentary behaviour with the promotion and encouragement of children's PA in the school environment showed that more active school personnel have more positive attitudes towards children's PA promotion and encouragement in schools. More active school personnel believed that their lead affects students' attitudes towards PA $(r=0.072-0.156, p<0.05)$ and that being active at recess facilitates a peaceful learning environment in the classroom $(r=0.064-0.072, p<0.05)$. Whereas more sedentary school personnel did not believe that being active at recess facilitates better relationships among students $(r=-0.069, p<0.05)$ and they did not encourage students to be physically active at recess $(r=-0.073, p<0.05)$. 


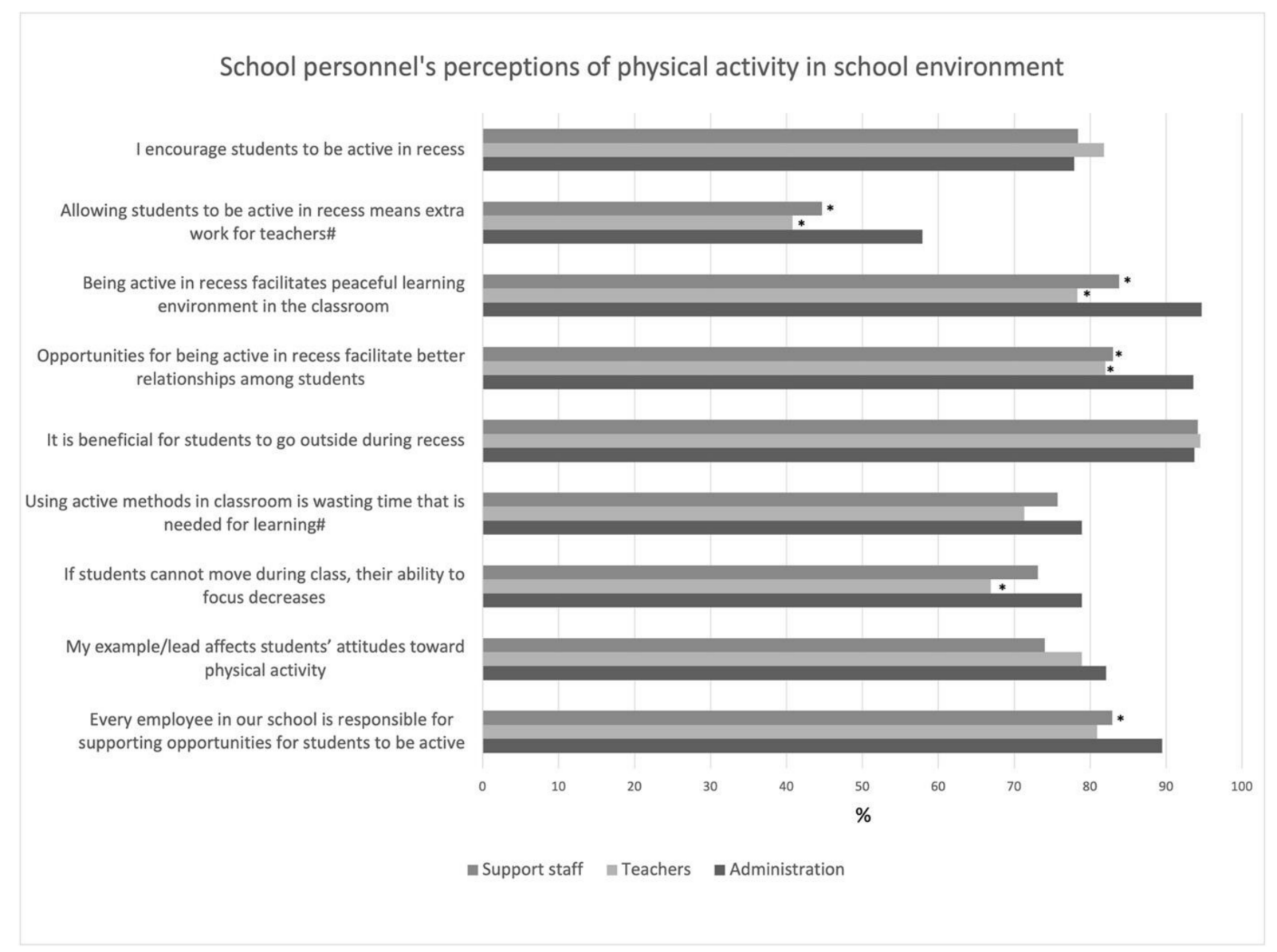

Figure 1. Administration, teachers, and support staff's perceptions about promoting and encouraging PA among students in schools. * Significantly different from administration $(p<0.05)$. \# Preferred answer was "strongly disagree or disagree" while in the other questions it was "strongly agree or agree".

\section{Discussion}

Teachers' and other school personnel's daily PA has not been widely examined in the world, and this study was the first to look at it in the Estonian context. The purpose of this study was to describe the PA levels of school personnel in Estonia and see whether there are relationships between PA levels and positive attitudes about providing PA opportunities for students throughout the school day. The majority of the school personnel met the minimum PA recommendation of 150 min of moderate PA in a week [4], and more active school personnel were more likely to promote and encourage physical activity among students in the school environment. Based on the results of the current study, school personnel who were more active throughout the day believed that their lead affects students' attitudes towards PA and being active at recess facilitates a peaceful learning environment in the classroom. Whereas more sedentary school personnel did not believe that being active at recess facilitates better relationships between students. Sedentary teachers also reported that they encouraged students less to be active during recess.

\subsection{Physical Activity}

Results showed that about $93 \%$ of participants in this study met the minimum PA recommendation of $150 \mathrm{~min}$ of moderate PA in a week [4] and about $51 \%$ met the recommendation of 300 min of moderate PA in a week. Even though most of the participants met the PA recommendation, school employees spent the majority of their day $(69.1 \%)$ being sedentary, and the amount of MVPA accounted for a small fraction (5.8\%) of the total accelerometer wearing time. The results of this study demonstrate that even when 
most of the day is spent sedentary, it is possible to meet the recommended PA levels. Findings of the current study are similar to those of previous studies, which have found that university workers in the UK spent up to 71\% of the working hours sedentary [36], and the university's office-based employees in New Zealand spent between $65 \%$ and $79 \%$ of working hours sedentary and only $4 \%$ accounted for MVPA [37]. When looking more closely at teachers, few studies in Brazil have found that about half of the public-school teachers are considered inactive $[8,14,16]$; similarly, teachers in this study spent more than two-thirds of their wakeful hours being sedentary.

The high percentage of people meeting the minimum weekly PA recommendation in this study can be accounted for by the fact that all the schools participating in the study are part of the Schools in Motion programme [22], in which the school personnel were made aware of the importance of PA. However, the study sample was quite large and many employees from the same school participated in the study; therefore, we cannot expect that only the fittest and most active employees participated. The results of this study demonstrate that more active school personnel have more positive attitudes about providing PA opportunities for students throughout the school day. This suggests that in order to provide school-based PA interventions, the whole school, including school personnel and students, needs to work together to find PA opportunities in schools that suit everybody. As teachers and other school personnel act as role models for students, it is important to provide PA opportunities for the personnel in the school environment (e.g., teachers going outside for recess, training programmes for school personnel, supporting the use of active transportation). The principal factor for including more PA opportunities throughout the school day can be having supportive school administrators who are aware of the benefits of PA and constantly educate themselves on different PA opportunities that can be provided for students throughout the school day. If the administrators are active and encourage PA within the school environment, they provide a positive example to teachers and students.

Based on the results of our study, school employees in the Schools in Motion programme are more active and feel healthier than the general population in Estonia [38]. More than half of the study participants in all groups reported doing at least moderate-intensity physical activity for at least $30 \mathrm{~min}$ at least twice a week. The same physical activity parameter for the general population in Estonia is only 39.9\% [38]. Most of the participants in this study reported being satisfied with their health, with the office staff being the least satisfied (61.8\%). When comparing this parameter to the general population in Estonia, only $50.2 \%$ reported that their health is good or rather good [38]. Even though almost all the participants in the study met the WHO's weekly PA recommendations, the time participants in every group spent sedentary was close to ten hours per day. The average sitting time for the general adult population in Estonia is $5.5 \mathrm{~h}$ per day, which is about half of the sitting time of the participants of this study [39]. The general population in Estonia has a similar indicator of sedentary behaviour per day when compared to other Nordic countries (Denmark 5.9 h, Finland 5 h, Sweden 5.8 h) [39]. The only Nordic country whose sitting time per day is higher and closer to the results of this study is Norway (7.1 h) [40]. A substantial difference in sedentary time between the study participants and the general population can be accounted for by the fact that the current study used accelerometers to measure sedentary time, whereas the data for the general population were self-reported. Previous studies have shown that people tend to underestimate their sedentary behaviour when asked to self-report their daily sedentary time [41,42].

\subsection{Perceptions about Students' PA}

All groups in this study had positive attitudes towards promoting and encouraging physical activity among students in the school environment. However, the administration's responses to some statements were significantly different compared to those of the teachers and support staff. Teachers and support staff work with students more than the administration; therefore, they may have a better understanding of students' behaviour. Similarly 
to a previous study, which found that $85 \%$ of the teachers in Italy agree that providing opportunities for engaging in PA during school day improves relationships among the students [43], this study found that over $80 \%$ of the teachers agreed with this statement. Over $80 \%$ of the teachers in a Brustio and colleagues [43] study also reported that providing PA opportunities for students during the school day did not negatively influence their teaching methods, while about half of the teachers in this study reported that allowing students to be active at recess meant extra work for teachers. Teachers who think that this means extra work for them should be educated on the effects of PA on students' attention and academic achievement. Previous studies have found that active recess positively influenced the learning environment and led to better focus on the classwork [44,45], which could mean that providing students with opportunities for PA throughout the school day would make teaching easier for teachers within the classroom.

\subsection{Strengths and Limitations}

The current study has several strengths and limitations that should be mentioned. The main strength of this study is that it is one of the few in the world and the first in Estonia to look at the PA habits of the school personnel in different types of schools in Estonia. Another strength of this study is that the study involved all types of school personnel and not just the teachers. Another strength of the study is that the PA levels were measured objectively with an accelerometer. However, the study also has some limitations. The first limitation of this study is the cross-sectional design of the study, which only allows looking at the relationships between variables and not the effect and causality. Moreover, the accelerometer used needed to be removed for water-based activities as the device was not waterproof, this could be a limitation for recording PA when participants' main choice of PA is swimming. Based on the results of this study, only six participants reported swimming on some measurement days; therefore, it did not have a major effect on the results. ActiGraph accelerometers do not measure MVPA accurately when subjects are cycling on a stationary bicycle or lifting weights. The study sample of schools participating in the Schools in Motion Programme can be both a limitation and a strength of the study. The limitation of this sample is the possibility of a selection bias. However, it can also be a strength as the results of this study provide more insight about the success of the programme and input for further developments. Most of the participants of the study were females $(87.1 \%)$; however, this is not a limitation as female teachers make up about $87-88 \%$ of all teachers in Estonia [27]. Therefore, male teachers are accurately represented in our study sample based on the general makeup of teachers' population in Estonia. Out of all the teachers who participated in the study, $14.8 \%$ were physical education teachers; however, their PA data and responses to the questionnaire did not differ from that of other subject teachers (data not shown).

\section{Conclusions}

This study found that school personnel who were more active had more positive attitudes towards PA, which demonstrates the importance of focusing on encouraging PA among school personnel. Physically active school leaders and administrators are essential as their attitudes and beliefs about PA can affect the school environment. School leaders are the decision-makers and have the power to make changes to the structure of the school day. They are able to implement new elements to the school day to promote the PA of children and other school personnel throughout the day. Based on the results of this study, school environments can benefit from evaluating the possibilities within their school to provide opportunities for school personnel, especially teachers, to be physically active. Schools should also educate school personnel about the benefits of PA for their health and the learning environment. When creating school-based PA interventions, the focus should not solely be on students but should also include the school personnel. Studies carried out among school personnel are scarce; therefore, longitudinal and intervention studies 
need to be carried out to assess the effect and causality of school personnel's PA habits and attitudes about PA on the PA habits of students more clearly.

Author Contributions: Conceptualisation, E.M., K.M. (Kerli Mooses) and M.K.; methodology, E.M., K.M. (Kerli Mooses) and H.T.; formal analysis, E.M. and G.M.L.; investigation, E.M. and H.T.; writing—original draft preparation, G.M.L.; writing—review and editing, M.K., K.M. (Katrin Mägi), H.T., K.M. (Kerli Mooses) and E.M.; supervision, E.M.; funding acquisition, M.K. All authors have read and agreed to the published version of the manuscript.

Funding: This study was supported by the project "Increasing physical activity of schoolchildren" funded by EEA grants (grant 2014-2021.1.05.20-0004) under the programme "Local Development and Poverty Reduction", co-financed by the Ministry of Social Affairs and the University of Tartu.

Institutional Review Board Statement: The study was conducted according to the guidelines of the Declaration of Helsinki and approved by the Medical Ethics Committee of the UNIVERSITY OF TARTU (approval no. 295/T-4, date of approval 26 August 2019).

Informed Consent Statement: Informed consent was obtained from all subjects involved in the study. Data Availability Statement: The data presented in this study are available on request from EM.

Acknowledgments: We would like to thank all the schools that participated in the study.

Conflicts of Interest: None declared.

Ethics Statement: The study was performed in accordance with the Declaration of Helsinki [28] and was approved by the Medical Ethics Committee of the University of Tartu, Tartu, Estonia, approval no 295/T-4.

\section{References}

1. World Health Organization. Physical Activity. Available online: https://www.who.int/news-room/fact-sheets/detail/physicalactivity (accessed on 8 June 2021).

2. Rezende, L.F.M.; Lopes, M.R.; Rey-López, J.P.; Matsudo, V.K.R.; Luiz, O.C. Sedentary behavior and health outcomes: An overview of systematic reviews. PLoS ONE 2014, 9, e105620. [CrossRef]

3. Kim, Y.S.; Park, Y.S.; Allegrante, J.P.; Marks, R.; Ok, H.; Cho, K.O.; Garber, C.E. Relationship between physical activity and general mental health. Prev. Med. 2012, 55, 458-463. [CrossRef]

4. World Health Organization. Who Guidelines on Physical Activity and Sedentary Behaviour: At a Glance; World Health Organization: Geneva, Switzerland, 2020; Licence: CC BY-NC-SA 3.0 IGO.

5. Prince, S.A.; Elliot, C.G.; Scott, K.; Visintini, S.; Reed, J.L. Device-measured physical activity, sedentary behavior and cardiometabolic health and fitness across occupational groups: A systematic review and meta-analysis. Int. J. Behav. Nutr. Phys. Act. 2019, 16, 30. [CrossRef]

6. Akinbode, R.; Lam, K.B.H.; Ayres, J.G.; Sadhra, S. Voice disorders in Nigerian primary school teachers. Occup. Med. 2014, 64, 382-386. [CrossRef] [PubMed]

7. Assuncao, A.Á.; Bassi, I.B.; Medeiros, A.M.; Rodrigues, C.S.; Gama, A.C.C. Occupational and individual risk factors for dysphonia in teachers. Occup. Med. 2012, 62, 553-559. [CrossRef]

8. Delfino, L.D.; Tebar, W.R.; Tebar, F.C.S.; DE Souza, J.M.; Romanzini, M.; Fernandes, R.A.; Christofaro, D.G.D. Association between sedentary behavior, obesity and hypertension in public school teachers. Ind. Health 2020, 58, 345-353. [CrossRef] [PubMed]

9. Moreno-Abril, O.; Luna-del-Castillo, J.D.; Fernández-Molina, C.; Jurado, D.; Gurpegui, M.; Lardelli-Claret, P.; Gálvez-Vargas, R. Factors associated with psychiatric morbidity in Spanish schoolteachers. Occup. Med. 2007, 57, 194-202. [CrossRef] [PubMed]

10. Yang, X.; Ge, C.; Hu, B.; Chi, T.; Wang, L. Relationship between quality of life and occupational stress among teachers. Public Health 2009, 123, 750-755. [CrossRef]

11. Daneshmandi, H.; Choobineh, A.; Ghaem, H.; Karimi, M. Adverse effects of prolonged sitting behavior on the general health of office workers. J. Lifestyle Med. 2017, 7, 69-75. [CrossRef]

12. Sheuch, K.; Haufe, E.; Seibt, R. Teacher's health. Dtsch. Arztebl. Int. 2015, 112, 347-356.

13. Baeriswyl, S.; Bratoljic, C.; Krause, A. How homeroom teachers cope with high demands: Effect of prolonging working hours on emotional exhaustion. J. Sch. Psychol. 2021, 85, 125-139. [CrossRef] [PubMed]

14. Brito, W.F.; dos Santos, C.L.; Marcolongo, A.A.; Campos, M.D.; Bocalini, D.S.; Antonio, E.L.; Silva Junior, J.A.; Tucci, P.J.F.; Serra, A.J. Physical activity levels in public school teachers. Rev. Saude Publica 2012, 46, 104-109. [CrossRef]

15. Dias, D.F.; Loch, M.R.; Gonzalez, A.D.; de Andrade, S.M.; Mesas, A.E. Insufficient free-time physical activity and occupational factors in Brazilian public school teachers. Rev. Saude Publica 2017, 51, 68. [CrossRef] [PubMed]

16. Santos, M.C.S.; de Andrade, S.M.; Gonzalez, A.D.; Dias, D.F.; Mesas, A.E. Association between chronic pain and leisure time physical activity and sedentary behavior in schoolteachers. Behav. Med. 2018, 44, 335-343. [CrossRef] 
17. Bogaert, I.; De Martelaer, K.; Deforche, B.; Clarys, P.; Zinzen, E. Associations between different types of physical activity and teacher's perceived mental, physical and work-related health. BMC Public Health 2014, 14, 534. [CrossRef] [PubMed]

18. Cheung, P.P.; Chow, B.C.; Parfitt, G. Using environmental stimuli in physical activity intervention for school teachers: A pilot study. Int Electron. J. Health Educ. 2008, 11, 47-56.

19. Cheung, P.P.; Chow, B.C. Association of school teachers' occupational and daily physical activity level in Hong Kong. Int. J. Sport Health Sci. 2012, 10, 23-29. [CrossRef]

20. Carson, R.L.; Baumgartner, J.J.; Matthews, R.A.; Tsouloupas, C.N. Emotional exhaustion, absenteeism, and turnover intentions in childcare teachers. Examining the impact of physical activity behaviors. J. Health Psychol. 2010, 15, 905-914. [CrossRef]

21. Cooper, K.; Barton, G.C. An exploration of physical activity and wellbeing in university employees. Perspect. Public Health 2016, 136, 152-160. [CrossRef] [PubMed]

22. Mooses, K.; Vihalemm, T.; Uibu, M.; Mägi, K.; Korp, L.; Kalma, M.; Mäestu, E.; Kull, M. Developing a comprehensive school-based physical activity program with flexible design—from pilot to national program. BMC Public Health. 2021, 21, 92. [CrossRef] [PubMed]

23. Cole, K.; Waldrop, J.; D'Auria, J.; Garner, H. An integrative research review: Effective school-based childhood overweight interventions. J. Spec. Pediatr. Nurs. 2006, 11, 166-177. [CrossRef]

24. Eather, N.; Morgan, P.J.; Lubans, D.R. Social support from teachers mediates physical activity behavior change in children participating in the Fit-4-Fun intervention. Int. J. Behav. Nutr. Phys. Act. 2013, 10, 68. [CrossRef]

25. Baranowski, T.; Perry, C.L.; Parcel, G.S. How individuals, environments, and health behavior interact. In Health Behavior and Health Education: Theory, Research, and Practice, 3rd ed.; Glanz, K., Rimer, B.K., Lewis, F.M., Eds.; Josset-Bass: San Francisco, CA, USA, 2002; pp. 165-184.

26. Haridus- ja Teadusministeerium. Õpetajad ja Koolijuht. Töösuhted. Available online: https://www.hm.ee/et/tegevused/ opetaja-ja-koolijuht/toosuhted (accessed on 8 June 2021). [Republic of Estonia Ministry of Education and Research. Teachers and School Leaders.].

27. Haridussilm. Õpetajad. Available online: https://www.haridussilm.ee/ee/tasemeharidus/haridustootajad/opetajad (accessed on 8 June 2021). [The Estonian Portal for Education Statistics Portal Haridussilm].

28. World Medical Association. World Medical Association Declaration of Helsinki: Ethical principles for medical research involving human subjects. JAMA 2013, 310, 2191-2194. [CrossRef]

29. Kantomaa, M.T.; Tikanmäki, M.; Kankaanpää, A.; Vääräsmäki, M.; Sipola-Leppänen, M.; Ekelund, U.; Hakonen, H.; Järvelin, M.R.; Kajantie, E.; Tammelin, T.H. Accelerometer-measured physical activity and sedentary time differ according to education level in young adults. PLoS ONE 2016, 11, e0158902. [CrossRef]

30. Migueles, J.H.; Cadenas-Sanchez, C.; Rowlands, A.V.; Henriksson, P.; Shiroma, E.J.; Acosta, F.M.; Rodriguez-Ayllon, M.; EstebanCornejo, I.; Plaza-Florido, A.; Gil-Cosano, J.J.; et al. Comparability of accelerometer signal aggregation metrics across placements and dominant wrist cut points for the assessment of physical activity in adults. Sci. Rep. 2019, 9, 18235. [CrossRef]

31. Peters, T.M.; Moore, S.C.; Xiang, Y.B.; Yang, G.; Shu, X.O.; Ekelund, U.; Ji, B.T.; Tan, Y.T.; Liu, D.K.; Schatzkin, A.; et al. Accelerometer-measured physical activity in Chinese adults. Am. J. Prev. Med. 2010, 38, 583-591. [CrossRef]

32. Migueles, J.H.; Cadenas-Sanchez, C.; Ekelund, U.; Nyström, C.D.; Mora-Gonzalez, J.; Löf, M.; Labayen, I.; Ruiz, J.R.; Ortega, F.B. Accelerometer data collection and processing criteria to assess physical activity and other outcomes: A systematic review and practical considerations. Sports Med. 2017, 47, 1821-1845. [CrossRef]

33. Sõritsa, D.; Mäestu, E.; Nuut, M.; Mäestu, J.; Migueles, J.H.; Läänelaid, S.; Ehrenberg, A.; Sekavin, A.; Sõritsa, A.; Salumets, A.; et al. Maternal physical activity and sedentary behaviour before and during in vitro fertilization treatment: A longitudinal study exploring the associations with controlled ovarian stimulation and pregnancy outcomes. J. Assist. Reprod. Genet. 2020, 37, 1869-1881. [CrossRef] [PubMed]

34. Freedson, P.S.; Melanson, E.; Sirard, J. Calibration of the computer science and applications, Inc accelerometer. Med. Sci. Sports Exerc. 1998, 30, 777-781. [CrossRef] [PubMed]

35. Kettner, S.; Kobel, S.; Fischbach, N.; Drenowatz, C.; Dreyhaupt, J.; Wirt, T.; Koch, B.; Steinacker, J.M. Objectively determined physical activity levels of primary school children in south-west Germany. BMC Public Health 2013, 13, 1-10. [CrossRef] [PubMed]

36. Clemes, S.A.; O'Connell, S.E.; Edwardson, C.L. Office workers' objectively measured sedentary behavior and physical activity during and outside working hours. J. Occup. Environ. Med. 2014, 56, 298-303. [CrossRef] [PubMed]

37. Keown, M.K.; Skeaff, C.M.; Perry, T.L.; Haszard, J.J.; Peddie, M.C. Device-measured sedentary behavior patterns in office-based university employees. J. Occup. Environ. Med. 2018, 60, 1150-1157. [CrossRef]

38. Reile, R.; Tekkel, M.; Veideman, T. Eesti Täiskasvanud Rahvastiku Tervisekäitumise Uuring 2018 (Health Behaviour Among Estonian Adult Population 2018); National Institute for Health Development: Tallin, Estionia, 2019.

39. European Commission. Special Eurobarometer 472: Sport and Physical Activity Report; TNS Opinion \& Aocial at the Request of the European Commission: Brussels, Belgium, 2017.

40. Norwegian National Surveillance 2; 2014-2015 (Sedentary Time Assessed by IPAQ). Available online: https://new. globalphysicalactivityobservatory.com/New\%20Country\%20cards/Norway.pdf (accessed on 28 September 2021).

41. Jefferis, B.J.; Sartini, C.; Ash, S.; Lennon, L.T.; Wannamethee, S.G.; Whincup, P.H. Validity of questionnaire-based assessment of sedentary behaviour and physical activity in a population-based cohort of older men; comparison with objectively measured physical activity data. Int. J. Behav. Nutr. Phys. Act. 2016, 13, 14. [CrossRef] 
42. Oviedo-Cavo, M.A.; Bueno-Antequera, J.; Munguia-Izquierdo, D. Measuring sedentary behavior during pregnancy: Comparison between self-reported and objectively measured. Matern. Child. Health J. 2018, 22, 968-977. [CrossRef] [PubMed]

43. Brustio, P.R.; Moise, P.; Marasso, D.; Miglio, F.; Rainoldi, A.; Boccia, G. Feasibility of implementing an outdoor walking break in Italian middle schools. PLOS ONE 2018, 13, e0202091.

44. Maykel, C.; Bray, M.; Rogers, H.J. A classroom-based physical activity intervention for elementary student on-task behavior. J. Appl. Sch. Psychol. 2018, 4, 259-274. [CrossRef]

45. Mavildi, M.F.; Drew, R.; Morgan, P.J.; Lubans, D.R.; Schmidt, M.; Riley, N. Effects of different types of classroom physical activity breaks on children's on-task behaviour, academic achievement and cognition. Acta Pædiatrica 2020, 109, 158-165. [CrossRef] [PubMed] 